\title{
Narrar la memoria y los exilios. Viaje e inmigración en Mar de olvido de Rubén Tizziani
}

\author{
Fernanda Elisa BRAVO HERRERA \\ Consejo Nacional de Investigaciones Científicas y Técnicas \\ Universidad Nacional de Salta (Argentina)
}

\begin{abstract}
RESUMEN
El objetivo de este trabajo es analizar, en la novela Mar de olvido (1992) del argentino Rubén Tizziani, la isotopía de las narraciones familiares sobre el viaje de inmigración a la Argentina. Este trabajo enfoca las problemáticas identitarias y sociales inscriptas en los diferentes relatos de los sujetos, vinculadas con la memoria, la identidad, el exilio y el olvido. El análisis reconstruye la configuración del relato como espacio de indagación y de formación de la identidad del sujeto, y el movimiento del viaje, real, simbólico o discursivo, como movimiento de reflexión metatextual y metanarrativa.
\end{abstract}

Palabras clave: memoria, exilios, inmigración, narración.

Narrating memory and exiles. Travel and immigration in Mar de olvido by Rubén Tizziani

\begin{abstract}
The purpose of this work is to analyze the concept of isotopy of family narratives concerning the journey of immigration in Argentina in the novel of Argentinian writer Rubén Tizziani. This work focuses on the social issues and the identities inscribed in the various stories of the subjects linked with memory, identity, exile and oblivion. The analysis reconstructs the configuration of the story as an area of investigation and formation of subjectivity and the travel (real, symbolic or discursive) as a movement of metatextual and metanarrative reflection.
\end{abstract}

Keywords: memory, exiles, immigration, narrating.

También yo desandé la ruta en busca del lugar en donde, se supone, comienza la memoria.

Rubén Tizziani, Mar de olvido 
La novela Mar de olvido del escritor y periodista santafesino Rubén Tizziani, publicada en 1992, se inscribe en un amplio corpus de la literatura argentina que recupera la historia de la inmigración como clave de la indagación alrededor de la problemática y deshilachada identidad nacional. Ya desde el título de esta novela se establece un diálogo con otras producciones literarias argentinas que también se proponen reconstruir, desde la ficción narrativa, esa instancia decisiva de la historia del país. Así, a partir del genotexto de 'mar', que remite al desplazamiento inmigratorio y al exilio que conlleva el mismo, y de la referencia al mecanismo indisoluble entre olvido y memoria que, parafraseando a Borges, son el anverso y el reverso de la misma moneda, se establece un contrapunto con Santo oficio de la memoria de Mempo Giardinelli (2004) publicada en 1991, con El mar que nos trajo de Griselda Gambaro (2001) y, elípticamente, con la novela de Daniel Moyano (2006), Libro de navios y borrascas publicada en el 1983. Todas estas producciones se proponen indagar la inmigración, no tanto como hecho concluido perteneciente a la Historia, sino más bien cuanto proceso en marcha, no terminado, que requiere una revisión continua y que interesa en tanto está vinculado con las historias de los individuos, es decir, como problematización de una memoria colectiva y familiar en una crisis aún no resuelta ni completamente definida. La inscripción narrativa atiende, por ello, la microhistoria y la historia desde abajo, tal como se concibe por Hobsbawn (2002) y por Sharpe (1991), rescatando, de este modo, voces anónimas y marginadas para ofrecer una múltiple perspectiva de la historia y de la memoria. Mar de olvido es, como las novelas anteriormente mencionadas, y como también otras producciones narrativas de Roberto Raschella, Antonio Dal Masetto, Liliana Bellone, María Angélica Scotti, Lermo Rafael Balbi, Héctor Bianciotti y Syria Poletti, entre otros, un relato de fundación tal como lo entiende Marc Augé, es decir que no se trata de un relato "de autoctonía", pues los relatos de fundación remiten, por el contrario, al movimiento y se refieren a un itinerario, a una huida, a una guerra, muchas veces simbólica, en última instancia, a "un trabajo que, incesantemente trasforma los lugares en espacios o los espacios en lugares" (Augé, 2000: 86) y forma los lugares de la memoria. Mar de olvido, entonces, se inscribe en esta producción en la que la palabra se configura como desciframiento de una identidad a la luz de lo que ya no se es, es decir desde la propia alteridad, desde una no-identidad, una no-mismidad, desde un olvido que se vuelve protagonista del viaje, sujeto de acción y de palabras y, paradójicamente, se construye desde la recuperación de la memoria. Ya desde el inicio de la novela de Tizziani esta contradicción dialéctica entre memoria y olvido se enuncia -tomando en préstamo un concepto de Cornejo Polar sobre la literatura hispanoamericana- como una totalidad contradictoria, una dialéctica que busca resolverse en el relato y que conforma la identidad de los sujetos, que integran una estirpe signada por el exilio como marca indeleble. Así, la voz narrativa, "Ella", encargada de transmitir la memoria familiar "para recuperar la olvidada resonancia de las palabras, el calor de los cuerpos, la imprecisa forma de los rostros" (Tizziani, 1992: 12), marca desde el 
inicio de su narración el principio constitutivo de esa totalidad contradictoria, conformada en la unidad entre la memoria y el olvido, al borrar las tradicionales oposiciones entre ambos:

Porque no siempre la memoria -la obsesión de atrapar, de retener- es el revés del olvido, sino, a veces, el olvido mismo: indecisa marea que empuja hacia una u otra orilla, nave descarriada que ronda una frontera ambigua, indefinida, que derrota al azar entre la niebla, sin referir si busca un puerto o el vacío. (Tizziani, 1992: 12)

La memoria, que inicialmente se propone como única certeza, al afirmarse que "sólo existe el pasado, la memoria" (Tizziani, 1992: 13), a medida que la palabra va construyendo el relato, es decir que con la reconstrucción progresiva que lleva a cabo la memoria con su narración de los restos, las huellas del pasado, se va desdibujando en su certeza y va evidenciándose su otro rostro, el del olvido. La voluntad de desciframiento que sostiene todo relato, especialmente todo relato de viaje que plantea el problema del tiempo y su relación con la identidad como principio de inteligibilidad, también comienza a derrumbarse, pues las limitaciones al mismo imponen un límite e instauran, así, otro exilio, esta vez referido al espacio del saber. El viaje, un viaje que no termina nunca, iniciado en un tiempo remoto, empedernido en el regreso, en la decisión de retener el pasado, desandando "la ruta en busca del lugar en donde, se supone, comienza la memoria" (Tizziani, 1992: 222) se revela, por ello, inútil, porque finalmente se evidencia la imposibilidad del regreso y la inevitabilidad de las pérdidas. La identidad se configura desde ese exilio, en ese espacio liminal de no-pertenencia completa a dos espacios signados, tensionados por la inmigración. La condición de extranjero es, pues, la marca que define y declina a los sujetos a partir de la ausencia, la nostalgia y el olvido:
Así que conozco lo que debieron de padecer usted y el músico cuando treparon al barco sabiendo que dejaban atrás un universo humilde, sin grandeza, pero donde podían sentirse, para lanzarse en pos de un horizonte ajeno, desconocido y, seguramente, inconquistable; sesenta años más tarde, mientras recorría martirizado por la inquietud y la nostalgia una ciudad que nunca sería mía, reconocí el antiguo, heredado estupor de la ausencia, la amarga, agobiante sensación de ser un extranjero. (Tizziani, 1992: 195)

El trabajo de la memoria, o, como diría Mempo Giardinelli, el "santo oficio de la memoria", se muestra finalmente, cuando se realiza el viaje de regreso a la tierra de origen de la familia, en la otra orilla, inútil, como el viaje mismo. La extranjería, la pérdida inevitable, la imposibilidad de recuperar y de conservar intacto aquello que fue determinan el no-retorno. El desciframiento del pasado en el relato del viaje implica descubrir, por una parte, "que el olvido es implacable y que sería imposible desentrañar las claves, el oculto significado de los signos" y, por otra, "que nunca se 
vuelve al hogar, al sitio abandonado; que descubrirse extranjero en su tierra, es el desmesurado precio de la ausencia" (Tizziani, 1992: 224-225). El relato, que se construye a partir de la fantasía de la perennidad del terruño, de los lugares de la memoria, va develando su enigma, su cifra: la permanencia no es de ese terruño, ya "dispersado por el viento, gastado por la lluvia, deshecho por la usura de los días" (1992: 224), sino de la condición de migrante, de extranjero en un fatal círculo en el que los navíos, los barcos se van sucediendo unos a otros, en "una eterna, repetida travesía" (1992: 274). El viaje, como el relato, como la memoria/olvido, se configuran desde una circularidad, desde una fatalidad que, como un misterio, signa la identidad de los sujetos migrantes, que "vencidos de antemano en una guerra desigual contra sueños imposibles, sólo aceptaríamos la desmesurada ambición de la utopía" (1992: 276). El recorrido de retorno, con sus extravíos y espejismos, no es más que un peregrinaje azaroso, circular, por una memoria que es también olvido, hecha de palabras y forjadora de mitos. El carácter fundacional de este relato radica en esta potencialidad creativa que permite construir tradiciones, mitos, remodelar un imaginario e imponer un horizonte de expectativas, obsesiones y quimeras. El relato polifónico, a cargo de diferentes voces que se van alternando mientras ofrecen no solo perspectivas diversas, sino también tonalidades y percepciones diferentes, se propone como un "monumento" en el sentido etimológico, es decir, como "expresión tangible de la permanencia o, por lo menos, de la duración" (Augé, 2000: 65). El viaje, desde esta perspectiva, opera como movimiento retrospectivo, ritual, con carácter sagrado, que permite pensar, junto al relato, como si fuera una "ceremonia", en el valor religioso de la continuidad de los espacios, de las relaciones y de la identidad.

Proponer un recorrido por Mar de olvido, y elípticamente por el corpus vinculado con la inmigración en Argentina, implica, entonces, indagar y tratar de descifrar el horizonte narrativo apoyándose en categorías complejas como sujeto, identidad, memoria, espacio, fronteras y nación, distinguiendo aquí la memoria colectiva, la genealógica y la histórica y, por tanto, en las configuraciones y representaciones de los lugares de la memoria, los restos simbólicos y las sedimentaciones de una memoria que construye y se construye en los relatos. Esta indagación implica, además, reflexionar sobre la constitución del canon literario argentino, marcado por la violencia en sus múltiples formas, ya desde la instancia fundacional de las crónicas o de El matadero de Echeverría. Una identidad no resuelta, un diálogo de muertos, en los espacios de la memoria y en los espacios antropológicos signados por la violencia simbólica que se conforma a partir del desplazamiento, de las pérdidas, de la extrañeidad instaurada al descubrirse ajeno, diferente en la errancia y en la marginalidad. Se trata, entonces, de configurar un mapa del canon en el que la violencia, tal como lo propuso Ricardo Piglia (1993) en La Argentina en pedazos, nace de esa migrancia, de ese exilio fundacional, de la itinerancia que se despega de una autoctonía e implica, por ello, una "desterritorialización" cultural e identitaria. La violencia que va delineando el 
canon literario argentino se despega, por tanto, de la marca social del "suelo", en tanto éste no es siempre determinante de una identidad relacional e histórica, sino más bien su "diferencia" y su "ausencia", condiciones que resultan ser fundacionales de una palabra desplazada en su búsqueda, ya tensionada en esa violencia.

La memoria, por otra parte, que opera en los procesos de textualización organizando el material discursivo vinculado con el fenómeno de la inmigración, se conforma como un "ideologema", según la propuesta de la sociocrítica montpelleriana de Edmond Cros (Cros, 1997). Esto determina, a su vez, que, en el texto literario, comprendido como texto cultural, se "memoricen" el sedimento de la socialidad y la referencia a un sujeto cultural, es decir, la instancia del discurso que implica el funcionamiento y la emergencia de una subjetividad y de un proceso de sumisión ideológica. El texto, en su modalidad narrativa, se presenta como un marco en el que se incorpora, organizada e interpretada, la experiencia, sea individual y colectiva, determinada por instancias socio-históricas y culturales. Esto implica que la memoria se conforme necesariamente como una narración y que necesite de una estructura narrativa para poder organizar el maremagnum de hechos y percepciones que se suceden y que se evocan en un espacio, tiempo, lenguaje y estructura semiótica a fin de garantizar su perdurabilidad, estabilidad y persistencia.

La narración de la memoria conduce a la transformación de las relaciones entre los sujetos, cuyas identidades y vínculos vienen remodulados y reconfigurados a partir de las perspectivas que les asignan un lugar en el tiempo y una función en los hechos. De este modo, la perdurabilidad de la narración implica, a su vez, la necesaria y oportuna "transformación" y adecuación a un relato que asigna identidades y confiere significancia a proyectos colectivos e individuales, especialmente marcados por la nostalgia y el exilio:

El viaje, el viaje. Il viaggio non finiva mai. Empezó tan atrás, en un lugar tan remoto, hubo en el medio tanto vacío llenado por la fábula, que al final sólo nos quedaron referencias confusas, testimonios enrarecidos por la distancia, el tiempo y la tristeza; sobre todo por la tristeza. Cuando uno extraña, algo cambia en los paisajes y en la gente, en algún alto del camino afloja el ánimo y se desliza una inadvertida falsedad, una mentira: error imperceptible al partir, que al llegar se hace enorme. Lo sé ahora que he visto la nostalgia de quienes, otra vez, siguen esperando el momento de volver. Pero ¿llegará la hora del regreso? (Tizziani, 1992: 221)

En la narrativa literaria argentina que presenta como núcleo central la problemática de la inmigración $\mathrm{y}$, con ella, la inscripción de la memoria (y del olvido) como estrategias narrativas, como sujeto de la enunciación y como genotexto fundacional de una palabra poética; todas estas cuestiones operan, manifestándose de diferentes maneras, pero manteniendo coincidencias en su 
indagación. La memoria, en estas narraciones, dentro de las cuales la novela de Tizziani y la de Giardinelli funcionan como paradigmas y modelos de una "tradición", se sedimenta y estratifica, confiriendo inteligibilidad a una problemática o, también, conduciendo a la crisis aquello que se consideraba inalterable y establecido. La memoria se presenta no solamente atendiendo la temática de la filiación y la necesidad de la búsqueda de raíces identitarias, sea individuales, familiares o colectivas, sino también, y principalmente, como problematización identitaria de una nación. De tal modo que las textualidades literarias -entre ellas Mar de olvido- que recuperan, narrativa y líricamente, a la inmigración y la reproponen, recuperando las voces que hasta entonces habían sido marginadas o estigmatizadas, porque extranjeras o subalternas, conforman un núcleo de indagación socio-histórica colectiva. La narración, viva, se instaura como dialéctica entre memoria y tiempo, y como un péndulo que oscila entre varias voces y sujetos (entre ellos, la memoria, "Ella", y el "Bandoneón"), entre diferentes espacios y tiempos, desplazando centros y, en todo caso, asignando a la palabra la centralidad por su función mediadora en esa compleja y siempre abierta dialéctica.

La memoria, entonces, se propone en Mar de olvido como una instancia discursiva y una estrategia textual y narrativa que permite, junto a la identidad y al olvido -otras categorías semióticas- la construcción de las representaciones del sujeto cultural, de los múltiples sujetos enunciativos, la perspectivación del mundo y del horizonte, las relaciones sociales e históricas. El espacio biográfico, tal como lo enuncia Leonor Arfuch (2010), se define en la(s) memoria(s) de los sujetos narrativos de Mar de olvido, permitiendo la construcción del mito del sujeto plural y disyuntivo, comprendido también "como una posición enunciativa dialógica" (Arfuch, 2010: 99) que se relaciona indispensablemente con la otredad. La otredad, que posibilita la salida del sujeto de sí mismo y abre la posibilidad a una relación con la "mismidad" diversa, otra, se declina en esta novela desde la memoria y desde el pasado que se recupera a través de ella, en vinculación con la propuesta de Derrida del "espectro" (1995). La otredad, y con ella la memoria, se modeliza como espacio y pasaje de reflexión de los vínculos entre los vivos y los muertos, los "espectros", de tal modo que la narración se hace cargo de la deuda y de la herencia, de la sujeción existente entre vivos y muertos. Esta categoría que tensiona y pone en diálogo la mismidad con la otredad conduce, en la estructura narrativa de Mar de olvido, a la desarticulación de la contemporaneidad y al anacronismo, es decir, a la conformación no lineal del relato que sigue los caminos, muchas veces tortuosos y lagunosos, de la memoria, de los recuerdos y evocaciones de los sujetos narrantes. Se trata, entonces, de una voluntad narrativa de dominio del tiempo y, por ello, de la vida:

¿Es que, si al fin pisamos la tierra prometida, podremos aceptar que la historia sucedió, que está escrita? 
Empedernido pueblo el mío, jugado entero en una pelea con el tiempo perdida de antemano. Se nos va la vida en la absurda apuesta de retener el pasado, de violentarlo para hacerlo presente, de conjurarlo a que reste, como si fuera posible que todo siga aconteciendo... (Tizziani, 1992: 221)

En Mar de olvido, por lo tanto, la narración -las múltiples narraciones de la(s) memoria(s) - se encadena, superpone, en las varias voces que muestran, esconden y evidencian la mismidad y la otredad, el vínculo indispensable con los muertos y con el instaurarse en el tiempo vivido y narrado para desentrañar el enigma de la propia existencia, del discurrir de la palabra. La legibilidad de este entrecruzamiento y de las relaciones, en el intento hermenéutico, evidencia la voluntad interpretativa y su condición compleja en tanto no se trata de una legibilidad transparente y unívoca. Efectivamente, no obstante persista una voluntad interpretativa de la historia familiar y de las varias historias que, como mosaicos, la componen, no siempre en Mar de olvido se impone una única línea y muchas veces las elecciones interpretativas parecen superponerse, contradecirse, completarse, entrar en conflicto, obliterar, colocar en elipsis nudos importantes del relato. Esta complejización de la legibilidad de la memoria se apoya también en su conformación como "secreto" que van heredando los distintos miembros de la familia en Mar de olvido, atendiendo, de este modo, la propuesta de Derrida. Esta categoría derridiana permite comprender a la memoria como una herencia, más específicamente como un secreto heredado, que necesita ser leído e interpretado para que pueda hacer legible un pasado y permitir que éste emerja en una línea temporal instaurada en el futuro (Saraceni, 2008). El pasado que emerge de ese secreto que se hereda -y que progresivamente se desvela en Mar de olvido- se conforma anárquicamente, deformado y heterogéneo a la vez (Deleuze y Guattari, 1980), mostrando con ello la complejidad de la memoria, de la narración y de la herencia-secreto discursivizada. En esta complejidad, la otredad y la mismidad se conjugan, celándose una en la otra, y mostrando, a su vez, cómo lo quieto se agita y fragmenta, revelando así una otredad en lo inmóvil (Foucault, 2000) y un trabajo de "excavación arqueológica", según la propuesta de Walter Benjamin, o de reconstrucción de genealogías y antigenealogías (Jodorowsky y Costa, 2011).

En Mar de olvido estas problemáticas se inscriben evidenciando la centralidad de la memoria sea como narración, sea como morfogénesis. El complejo proceso de (dis)continuidades en los varios relatos, tendiente a re-construir la(s) historia(s) de la familia -y, a través de la metáfora y de la elipsis, de la nación- muestra cómo el pasado se reinterpreta y recupera El mecanismo tendiente a esto se apoya en una dialéctica de selección del pasado, que recupera de éste algunos "fragmentos" e "imágenes", descartando otros, para ofrecer un relato de (re)interpretación de los mismos. El devenir colectivo (familiar) e individual (Amado y Domínguez, 2004) se despliega en Mar de olvido en esa "excavación arqueológica" de un pasado que se ofrece como testimonio y herencia. Los olvidos y disoluciones, en los silencios y 
fragmentos no-dichos de la novela de Tizziani no son negaciones del pasado, sino modelizaciones del mismo en función de una(s) líne(s) interpretativa(s) y son, por ello, evidencia de conflictos y espacios semióticos convergentes. El devenir familiar en Mar de olvido puede interpretarse según una "metagenealogía" (Jodorowsky y Costa, 2011) y ofrece, además, la posibilidad de plantearse no solo como lectura del colectivo social más amplio, sino también como estrategias de desciframiento de la narración y, de este modo, del hecho literario, del narrar en su faz más amplia.

La recuperación de esos "relámpagos congelados", que arman la memoria, se despliega en una narración que se configura desde lo biográfico y lo autobiográfico: Mar de olvido se presenta así como una saga que reconstruye un "árbol genealógico" en el relato de los sucesos en el que son protagonistas algunos miembros de diferentes generaciones de una misma familia. Este relato traza metonímicamente, a través de la recuperación de esos fragmentos, la historia del país y, en forma más amplia, propone un relato, se podría decir "bíblico", del "mundo". Efectivamente es significativo que el relato de recuperación de la historia familiar en Mar de olvido se despliegue en siete días con sus siete noches, entroncándose simbólicamente con la tradición bíblica del Génesis, que relata el origen del mundo en siete días. La palabra aquí es palabra fundacional como la del Génesis, y el mundo que se "crea" encierra ya una expulsión de un paraíso. El mito del paraíso perdido es una utopía que recorre la literatura de inmigración y de exilio y en Mar de olvido se conforma, además, como el origen de la narración, del relato "de quienes se reconocen testimonio, permanencia, memoria de una estirpe que ha elegido el abandono, la confusión, el olvido" (Tizziani, 1992: 286). El paraíso original perdido, como lugar de utopía, se desplaza, como la memoria y la misma condición de exiliados, de ese espacio de oportunidades que es América, para los emigrantes, al pueblo de origen, idealizado, para los inmigrantes y sus descendientes. La realidad se vuelve mítica y si no llega a realizarse esa performance positiva a través de la travesía de la nostalgia, es "desdeñada en nombre de un mundo tan lejano como imaginario, inmutable en su arbitrario corazón, pero, en verdad, perdido para siempre" (Tizziani, 1992: 169). El paraíso perdido que en Mar de olvido se construye es el de "un pueblo sin recuerdos, porque los que eligieron conservar -crónicas vulgares de villorrios miserables, de valles yermos y pedregosos- no les servirían a una estirpe que iría a enfrentar el horizonte estremecedor de la llanura" (Tizziani, 1992: 169). La pobre herencia de un espacio imaginado se instaura en los contrastes, múltiples porque se dirigen en un contrapunto dialógico al espacio real y al nuevo espacio que se espera conquistar. La migrancia del sujeto en estos espacios complejiza su extrañamiento, ya que su exilio se impone también en las representaciones del imaginario. Las miradas de los viajeros, que sostienen el relato, múltiples en Mar de olvido, pueden, en algunos casos, como en el de Marietta, la fundadora de una estirpe, y por tanto de una maldición, de una condena a causa del extravío, de la absurda quimera del viaje, quedarse prisioneras de un espacio fundamentalmente relacional e imaginario. 
Si en algunos sujetos de la estirpe esa prisión está marcada por el pueblo y sus "insuperables límites" (Tizziani, 1992: 132), en todos la utopía de la nueva tierra y del regreso al pueblo de origen constituye la prisión más fuerte, porque estos espacios no se inscriben en la realidad pues son "un imaginario paraíso que, ya en el barco, comenzó a tomar las formas de la fantasía, el color vibrante y luminoso del ensueño; falsa memoria que desdibuja las estrechas fronteras de un mundo avaro" (Tizziani, 1992: 130).

En Mar de olvido, entonces, la mirada hacia atrás enfrenta a los sujetos narrativos con "espectros" que, más allá de contribuir a interpretar las huellas y los vestigios del pasado, interpelan en relación con los "mandatos" familiares, un equipaje algunas veces pesado: "eso cargué al partir: vergüenza, incertidumbre, promesas ni traicionadas ni cumplidas, jirones de orgullo, miedo, una agobiante sensación de acoso, el eterno instinto de sobrevivir" (Tizziani, 1992: 283).

La mirada se vuelve necesariamente sobre la fragmentación identitaria, los conflictos, las adaptaciones, el regreso o los imposibles regresos dejados como herencia a futuras generaciones. La revisión del pasado en la narración implica tramar y desatar imágenes identitarias y memorias construidas desde la inmigración y definidas en las discontinuidades y deformaciones impuestas por los olvidos y los exilios. Así el relato es ese complejo discurrir hecho de "fragmentos que el hijo fue recogiendo y que muchos años más tarde le servirían para hacer una historia, reconstruir un poco el itinerario de su vida -la del hombre-, esa especie de fatalismo que lo hizo caminar sin pausa desde la niñez" (Tizziani, 1992: 189). La memoria familiar, conformada como un mandato dejado en herencia, se reactiva a través de la emigración de regreso, del viaje que emprende Martín cruzando el océano y también a través del relato, por la memoria y el olvido, revelando el exilio que conduce a la tierra de origen de la familia.

El mar funciona en esta novela de Tizziani -y en otras producciones literarias argentinas que tratan la temática de la inmigración- como una metáfora del olvido y de la memoria, del tiempo que transcurre, del espacio onírico no solo del emigrante sino de la familia, y, por tanto, en horizonte del imaginario colectivo. El nadar, el navegar por las aguas del mar y de la memoria son comparables con el transcurrir en el relato, es decir, con el narrar. Así, el agua (el mar), espacio onírico y símbolo del inconsciente colectivo, deviene también metáfora de la escritura y de la literatura. Olvido y memoria, desde los valores del mar, son espacios y paisajes que permiten (re)significar el pasado, estructurar narrativamente la memoria y ofrecer con el relato una explicación del transcurrir del tiempo, en la metáfora del río, que "era algo más que un lenguaje indescifrable; que hacía fluir la vida, pero también la muerte" (Tizziani, 1992: 60), y que es también imagen del río que los acoge en el nuevo mundo, representativo de la Argentina.

La memoria en Mar de olvido se configura desde múltiples (dis)continuidades que evidencian en la narración, construida en el mosaico de los varios relatos, las traiciones, los actos de coraje de fidelidad, las pérdidas y el atesoramiento de 
fragmentos y relámpagos de un pasado que se reactualiza en el relato y en la vida de los sujetos. El pasado se instaura en el presente de la narración que deviene atemporal y anacrónica por ello. La escritura y la oralidad conforman un núcleosostén de la novela y del recorrido vital de los miembros de la estirpe, herencia que recoge Martín, el último descendiente de la familia, cuya labor consiste en "destejer" y "tejer" ese relato complejo de pecados, culpas, secretos que emergen de los monólogos, de las conversaciones, y también de lo no-dicho, de las elipsis:

Sólo años más tarde, cuando empecé a desenredar esa impenetrable trama que era la historia de la familia (no porque alguien la contara, allí todo el tiempo se escamotearon pasados vergonzosos, sino por conversaciones escuchadas al pasar cuando la gente se juntaba para algún aniversario, por rencores mal disimulados, quejas que las víctimas dejaban caer como al descuido, por los soliloquios de mi padre cada vez que el insomnio lo sacaba de la cama en mitad de la noche y lo hacía caminar durante horas por la galería, tan metido en el recuerdo, que ni cuenta de que hablaba debía de darse, mucho menos de que lo hacía en voz lo bastante alta como para ser escuchado desde cualquier lugar de la casa), se me ocurrió que quizá la abuela buscara ocultarse; acosada por antiguos remordimientos, por pecados que, en una de ésas, le dolían, injusticias que habían plantado el odio entre los hijos. (Tizziani, 1992: 50)

La memoria resulta ser, junto con la palabra, a veces obliterada y elíptica, la única herencia, la sola posesión, que permite tensionar y unir tiempos y espacios distantes, rescatando el horizonte del imaginario que fundó el relato y que se originó en la inmigración. La memoria no solamente recoge el pasado o las narraciones y explicaciones/interpretaciones de éste, sino también las idealizaciones y las falsas ilusiones, entre ellas, la primera, creada en el momento de emigrar, es decir la convicción falsa de que en el momento de dejar la tierra de origen definitivamente "fuimos hasta el otro lado del mar como quien va al mercado del pueblo vecino a vender la fruta o las ovejas; tan persuadidos del retorno, que en el final, a la hora de hacer el balance de lo ganado y lo perdido, sólo rescataríamos la gastada esperanza de contemplar por última vez el paese" (Tizziani, 1992: 130).

El regreso, tensionado entre el deseo y la imposibilidad, es una isotopía que signa la conformación de la memoria y la concepción del exilio en Mar de olvido. Exilio y olvido se configuran desde la imposibilidad del regreso a la tierra de origen, en lucha con los "amenazantes fantasmas del ayer en el sitio añorado" (Tizziani, 1992: 221), es decir, con los "espectros", con la fatalidad de la ausencia y la distancia. Esta imposibilidad de regresar al pueblo de origen, que es la imposibilidad de deshacer en el tiempo y en el espacio un desplazamiento, frustra un mandato familiar impuesto a través de generaciones, junto al relato de una memoria colectiva. De esta manera, el viaje se revela inútil y signa, en forma indeleble, la condición de extranjero del sujeto. El mandato familiar, no obstante la imposibilidad del regreso a nombre de los muertos que no han podido hacerlo, 
continúa imponiéndose, del mismo modo que se erige la palabra contra el silencio, aun cuando éste aparentemente logre regir la instancia decisiva en la conformación identitaria. El mandato familiar se revela en ese no-regreso, en la recuperación del pasado, en el exilio que se coloca como signo identitario de la estirpe:

Entonces, también yo padecí temores y ansiedades, desamparo, la agobiante sensación de que, valiera o no la pena, no me quedaba otra alternativa que seguir el rastro de una antigua, macabra fantasía: la de conservar intacto el espacio conocido para que fuera garantía del retorno; como si se dejara la comida al rescoldo, esperando que al volver siguiera tibia. Pero no regresaron y el mundo envejeció, se hizo cenizas [...]

Así que eso había: el mismo puerto sin memoria, los mismos callejones y recovas, la taberna en que bebió un vaso de vino y, más tarde, una grappa para darse coraje. Y aunque palpé muros carcomidos por siglos de sol y tempestades, junto a los cuales debió de caminar, no hallé huella alguna de su paso, ningún mensaje atravesó intacto el tiempo para manifestarse cuando fuera evocado, ningún temblor de la mano me reveló que, quizás, allí, por un momento, él había recostado su cansancio. (Tizziani, 1992: 224-225)

La narración, que se coloca como sostén de la memoria, entra en aparente conflicto con el silencio, que parece signar el olvido. Esta oposición en realidad oculta la conformación de memoria y olvido, de palabra y silencio como elementos constituyentes de una misma ontología, de un mismo horizonte identitario y narrativo. El silencio se preanuncia como olvido y, por la dialéctica que la signa, es una cara más de la memoria y del relato, del proceso interpretativo. La imposibilidad del regreso, no obstante esto, marca el inicio del silencio en la evocación de la tierra y del pasado, pero solamente porque ya se ha dicho todo lo que debía decirse, es decir, porque ya concluyó el rito de evocación a través de la palabra iniciado por "Ella" al comienzo de la novela. Así "la hora de callar, de concluir las evocaciones; porque todas las palabras que de ahí en adelante se dijeran serían sólo un ruido hueco incomprensible. Más que recuerdo, olvido" (Tizziani, 1992: 285) es otra forma más de la narración, una parte necesaria en su travesía.

De esta forma, en Mar de olvido las narraciones, tensionadas entre la memoria y el olvido, a partir de un relato polifónico, obliterado, en elipsis y metonímico, rearma no solo la historia de la inmigración familiar que interesa a tres generaciones de la misma, sino también el proceso de formación identitaria que incide en cada uno de los sujetos que narran y las diversas representaciones y configuraciones del "viaje" por la memoria y el olvido. En esta novela, el viaje, en sus movimientos pendulares y con una valencia colectiva, comprende desplazamientos y recorridos por una memoria fragmentada y en tensión dialógica con el olvido. Los verdaderos sujetos y protagonistas de esta novela metatextual son, entonces, las varias y contradictorias narraciones del horizonte del viaje, fundamentalmente discursivo, tendiente a reformular una historia que permita definir una identidad deshilachada 
en los múltiples exilios y desplazamientos. El desarraigo conforma el núcleo complejo que activa y modeliza la narración de esta novela, declinada, no obstante el imperativo de la memoria, en la tensión del olvido "implacable" que, como la memoria y el mismo ejercicio narrativo, posee una función semiótica e interpretativa de los signos y de la misma palabra, ordenando el caos de la existencia y el transcurrir del tiempo y los espacios. El discurso narrativo del viaje se vuelve sujeto y la inmigración deviene pre-texto de indagación identitaria que evidencia el proceso de configuración y construcción a partir del relato y de la misma narración. El viaje se conforma en Mar de olvido como un peregrinaje especular y circular, marcado por las tensiones fundacionales y definitorias de la partida, el desarraigo, los múltiples exilios, el imposible regreso. La narración del mismo, con sus variadas facetas, abre posibilidades de reflexión metatextual y metanarrativas que proponen un viaje por el mismo hacer-literario, como relato de viaje y como forma de construcción de un espacio semiótico y antropológico.

\section{BIBLIOGRAFÍA}

AGUILUZ IBERGÜEN, Maya.

2009 El lejano próximo. Estudios sociológicos sobre extrañeidad. Barcelona: Anthropos.

AmAdo, Ana y Nora Domínguez.

2004 Lazos de familia. Herencias, cuerpos, ficciones. Buenos Aires: Paidós.

ARFUCH, Leonor.

2010 El espacio biográfico. Dilemas de la subjetividad contemporánea. Buenos Aires: Fondo de Cultura Económica.

AUGÉ, Marc.

2000 Los "no lugares. Espacios de anonimato. Una antropología de la sobremodernidad. Barcelona: Gedisa.

BRAVO HERRERA, Fernanda Elisa.

2014 "La inmigración italiana en Argentina entre la memoria y el olvido" en Grillo, Rosa Maria - Perugini, Carla (ed.). El olvido está lleno de memoria. Salerno: Oèdipus, pp. 65-98,

CROS, Edmond.

1997 El sujeto cultural. Sociocrítica y psicoanálisis. Buenos Aires: Corregidor.

De Certau, Michel.

1990 L'invention du quotidien. Arts de faire. Paris: Gallimard.

DELEUZE, Gilles y Félix GUATTARI.

1998 Mil mesetas. Capitalismo y esquizofrenia. Valencia: Pre-Textos. 
DE ROSA, Ornella y Donato VerRastro (ed.).

2007 Appunti di viaggio. L'emigrazione italiana tra attualità e memoria. Bologna: Il Mulino.

DERRIDA, Jacques.

1995 Espectros de Marx. El estado de la deuda, el trabajo del duelo, la Nueva Internacional. Madrid: Editorial Trotta.

FOUCAULT, Michel.

2000 Nietzsche, la genealogía, la historia. Valencia: Pre-textos.

GAMBARO, Griselda.

2001 El mar que nos trajo. Buenos Aires: Grupo Editorial Norma.

GIARDINELLI, Mempo.

2004 Santo oficio de la memoria. Buenos Aires: Ficcionario.

HoBSBAWM, Erik.

2002 "Sobre la Historia desde abajo" en Sobre la Historia. Barcelona: Crítica, pp. 205-219.

JODOROWSKY, Alejandro y Marianne COSTA.

2011 Metagenealogía. El árbol genealógico como arte, terapia y búsqueda del Yo esencial. Buenos Aires: Sudamericana.

MAGNANI, Ilaria.

2012 "L’onere di ricordare" en Tizziani, Rubén. Il mare dell'oblio. Salerno: Oèdipus, pp. 7-22.

MOYANO, Daniel.

2006 Libro de navios y borrascas. Buenos Aires: Gárgola.

PIGLIA, Ricardo.

1993 La Argentina en pedazos. Buenos Aires: Ediciones de la Urraca.

SARACENI, Gina.

2008 Escribir hacia atrás. Herencia, lengua, memoria. Rosario: Beatriz Viterbo Editora.

SHARPE, Jim.

1991 "Historia desde abajo" en Burke, Peter. Formas de hacer Historia. Madrid: Alianza, pp. 38-58.

TIZZIANI, Rubén.

1992 Mar de olvido. Buenos Aires: Emecé. 